\section{Cochrane access}

$\mathrm{C}$ anadians will obtain free Internet access to full-text reviews in the John Wiley \& Sons Ltd. Cochrane Library for the remainder of 2009.

The 9-month pilot project was made possible by a one-time contribution from a federal organization, which requested anonymity because it cannot commit to long-term funding for a full national subscription, which costs roughly $\$ 500000$ annually, says Dr. Jeremy Grimshaw, director of the Canadian Cochrane Network and Centre based in Ottawa, Ontario, and professor of medicine at the University of Ottawa.

For Canada's licence to be extended beyond the pilot, a more stable and sustained source of funding is necessary, Grimshaw adds. "It's peanuts in the global health care system."

Among nations that currently purchase national licences are the United Kingdom, India and Poland. The library's content is also available free to World Bank-designated "low-income countries."

The Cochrane Collaboration, which runs the library worldwide, was founded in 1993 with a mandate to make up-to-date, evidence-based information about health care accessible to everyone. It does so through its library, the most prominent component of which is a database of systemic reviews of healthcare interventions conducted by voluteer experts. Each review is prefaced by a short summary in lay language.

About $10 \%$ of Canadians have had access to the library through a "patchwork" of provincial or institutional subscriptions, at about $80 \%$ of the cost of a national licence, Grimshaw says, adding that about 200000 Canadians accessed the library in 2008, while about 50000 unsuccessfully sought to access it.

Physicians will be among the primary beneficiaries of increased access, said Dr. Sam Shortt, Canadian Medical Association director of knowledge transfer at a press conference announcing the pilot. "I think I can say without contradiction that they will all absolutely welcome this access."

Karen Macdonell, librarian and comanager of the College of Physicians and Surgeons of British Columbia concurred. While physicians in BC have had access to the library for 3 years, those in other provinces, and other health care practitioners in $\mathrm{BC}$, have not, she said. "It certainly levels the playing field for clinicians in Canada."

\section{Expanded authority}

$\mathrm{T}$ he College of Physicians and Surgeons of Ontario will be allowed to directly observe the practices of doctors in out-of-hospital facilities over the course of investigations into complaints against physicians.

The new authority, granted under amendments to the province's Regulated Health Professions Act, allows the college to develop procedures "providing for the direct observation of a member in his or her practice, including the direct observation by inspectors of procedures, during the course of an inspection or examination."

It also empowers the college to "make reasonable inquiries of any person, including the member who is the subject of the investigation, on matters relevant to the investigation." Physicians must "cooperate fully with an investigator."

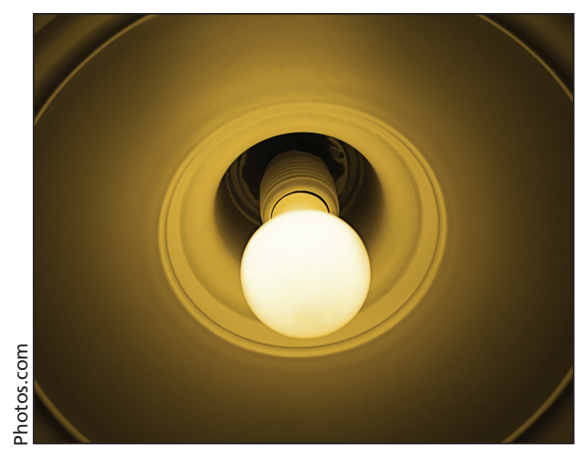

Allowing investigators to directly observe physicians in practice should "strengthen patient safety," says Neala Barton, spokesperson for Ontario Minister of Health and Long-Term Care David Caplan.

Registrar Dr. Rocco Gerace says the College has found itself handcuffed in past investigations. In cases currently before the courts that pertain to cosmetic procedures, doctors have refused to speak with college representatives. - Claire Biddiscombe, Ottawa, Ont.

DOI:10.1503/cmaj.090739

\title{
More news @cmaj.ca
}

Clinics: Canadian Blood Services will launch a pilot project to determine the effectiveness of new staffing models and procedures for blood donor clinics. - Claire Biddiscombe, Ottawa, Ont.

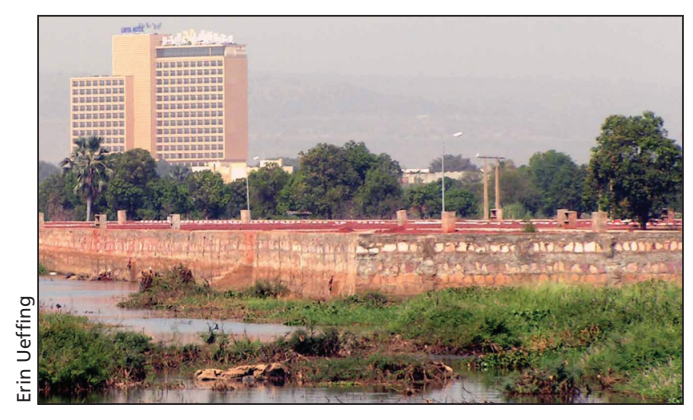

Dispatch: Motorcycle, motorcycle, goat, motorcycle. The contrast between urban and rural Africa, and their contrasting health needs, is striking. - Erin Ueffing, Ottawa, Ont.

DOI:10.1503/cmaj.090737 